\title{
Olhos passageiros
}

\author{
EDUARDO VIANA VARGAS
}

Universidade Federal de Minas Gerais, Belo Horizonte, Minas Gerais, Brasil

\section{DOI 10.11606/issn.2316-9133.v27i1p201-211}

Aberto na de década1950, em pleno período colonial, um caminho de ferro corta o norte de Moçambique. Desde então, e de maneira intermitente por conta da guerra de Independência e da dos 16 anos, ele conecta o porto de Nacala, a leste, às férteis regiões de Cuamba e Lichinga, a oeste. Por ele passa há décadas um comboio que leva gente, sobretudo macuas, de Nampula a Cuamba. É o principal meio de transporte das pessoas e dos produtos de machamba entre os inúmeros povoados da região, a mais populosa do país. Este comboio de gente que por muito tempo trocou o sal pelo açúcar, como notou Licínio Azevedo, hoje cede passagem aos inúmeros comboios de carvão. Nos últimos cinco anos o caminho de ferro foi refeito e ampliado. Agora ele atravessa o Malaui e chega às minas de carvão de Tete, o foco da corrida ao carvão que levou grandes conglomerados mundiais, com destaque para a mineradora Vale, a extrair carvão mineral em Moçambique. Extraído em escala sem precedentes, desde 2016 o carvão é transportado em numerosos comboios incrivelmente grandes pelo caminho de ferro do norte, antes de ser embarcado para alimentar siderúrgicas e termoelétricas na China e na Índia. O comboio de gente já não circula mais tanto quanto circulava: reduziram as viagens semanais; ele não para mais em muitos lugares onde antes parava: fecharam muito apeadeiros; ele também não autoriza mais o embarque de tantos utentes e seus pertences quanto antes se permitia: agora está tudo mais organizado, disciplinado. Dizem que o comboio ficou mais moderno. Decerto ficou mais raro.

Era madrugada de terça-feira, 06 de dezembro de 2016, quando embarquei com Júlio Paulino, um de meus amigos moçambicanos, na estação de Nampula. Era minha quinta ida a Moçambique, mas era também a primeira vez que conseguia tomar o comboio. Era verão e o dia estava quente e limpo. Afora o único vagão da primeira classe, o comboio estava cheio. Chegamos a Cuamba no final da tarde e regressamos dois dias depois. Entre ida e vinda, foram cerca de 20 horas em meio a paisagens inigualáveis e a pessoas marcantes e acolhedoras.

Composto com fotos inéditas, Olhos Passageiros $\# 1$ abre uma série de ensaios feitos com retratos que tirei de mais de uma centena destas pessoas enquanto o comboio circulava indo ou 
vindo de Nampula a Cuamba. Ele é parte de uma pesquisa mais ampla que estamos realizando em Moçambique desde 2014 no contexto do Programa Pro-Mobilidade CAPES/AULP sobre as controvérsias sociotécnicas implicadas na implantação do Corredor de Nacala.

Sou grato à CDN, que autorizou a circulação pelo comboio, ao Borges Jorge e ao Inocêncio Francisco, que fizeram a mediação com passageiros e passageiras, e sobretudo a Abel Paulo, Abodul Arlindo, Abubacar Abodolamo, Adamo Cataro, Adelino Alberto, Adriano André, Afonso Fernando, Alex Luís, Alfredo Francisco, Alves Missomal, Aly Momade, Amado Mussa, Amândio Manuel, Amelia Augosto, Amido Momade, Ana Raimundo, Anabela Matola, Anabela Matola, Andrade Vaykey, Angela Lopes, Anifa Abacar, Anita Amoren, Anselmo Pinto, Arminda João, Asanine Celestino, Augosto Antonio, Azania Carlos, Bager Antônio, Beatriz Bomba, Benedito Gito, Benito Nordino, Bento Esfraimo, Carlos Alberto, Carlota Jorge, Carolina Nsseu, Carriço Massinga, Castelo Mário, Celestina Alberto, Celestino Amoren, Delfim Saide, Desalio Alberto Tovela, Dionezio Bernardo, Edmilsom Campos, Elias Rosário, Elisa Joaquim, Ema José Salimo, Ermelinda Afonso, Ernesto Joaquim, Esmilarda Carlos, Esperança João, Ester Cotinho, Euzebio Daniel, Fatima Ramadane Amoren, Felomena Manuel, Fez Francisco, Fidelga Lopes, Fidnécio Julio, Fina Victor, Flex Joaquim, Francisco Fernando, Genito Alberto, Graça Samuel, Hermenegildo Iampita, Inocêncio Tomás, Isaura Rosário, Jacinto Alfredo João, Jaclene Zacaria, Jaimito Joaquim, Janete Bernardo, Jorge Lenson, José Lourenço, Josefina Pés, Juma Esimila, Juma Momade, Liquilila Daimo, Lourenço André, Lúcia Ernesto, Luiza Ernesto, Lurdes Cumua, Manuel Citora, Manuel Chale, Maria do Céu Salvador, Marinjane Bachir, Mário José, Mercia Manuel, Miguel Gastomo, Milenio Carlos, Naiscemento Lodrequis, Nelson Faustino, Nercio Luís, Noemia Augosto Helias, Orgines Jorge, Orlando Mona, Osvaldo Domingos, Pedro Carlos Bernardo, Pedro Oscar, Pedro Salvado, Piedade Charles, Queto Mamoede, Quimildo Damião, Ragide Alberto, Ramadane Amoren, Saide Arfaia, Saíde Tomas, Salvador Munambo, Sefinia Joaquim, Sifa Juma, Sonia Joaquim, Sorinha Juma, Tereza Daniel, Valdo Saide, Valodia João, Victória Bento, Zunoto Manuel e a seus filhos e filhas, que autorizaram ser fotografadas. São deles e delas os retratos.

Olhos passageiros, faces de outro modo gloriosas, resistentes do comboio do norte. 
Eduardo Viana Vargas

Graduado em Ciências Sociais pela Universidade de Campinas (1986), mestre em Antropologia Social pela Universidade Federal do Rio de Janeiro (1992) e doutor em Ciências Humanas: Sociologia e Política pela Universidade Federal de Minas Gerais (2001), realizou pós-doutorado no Centre de Sociologie de l'Innovation da École des Mines de Paris em 2005. Atualmente é Professor Associado de Antropologia na FAFICH, UFMG, onde atua desde de 1996 e onde coordena o Laboratório de Antropologia das Controvérsias Sociotécnicas.

Recebido em 27/02/2018 Aceito para publicação em: 23/11/2018 

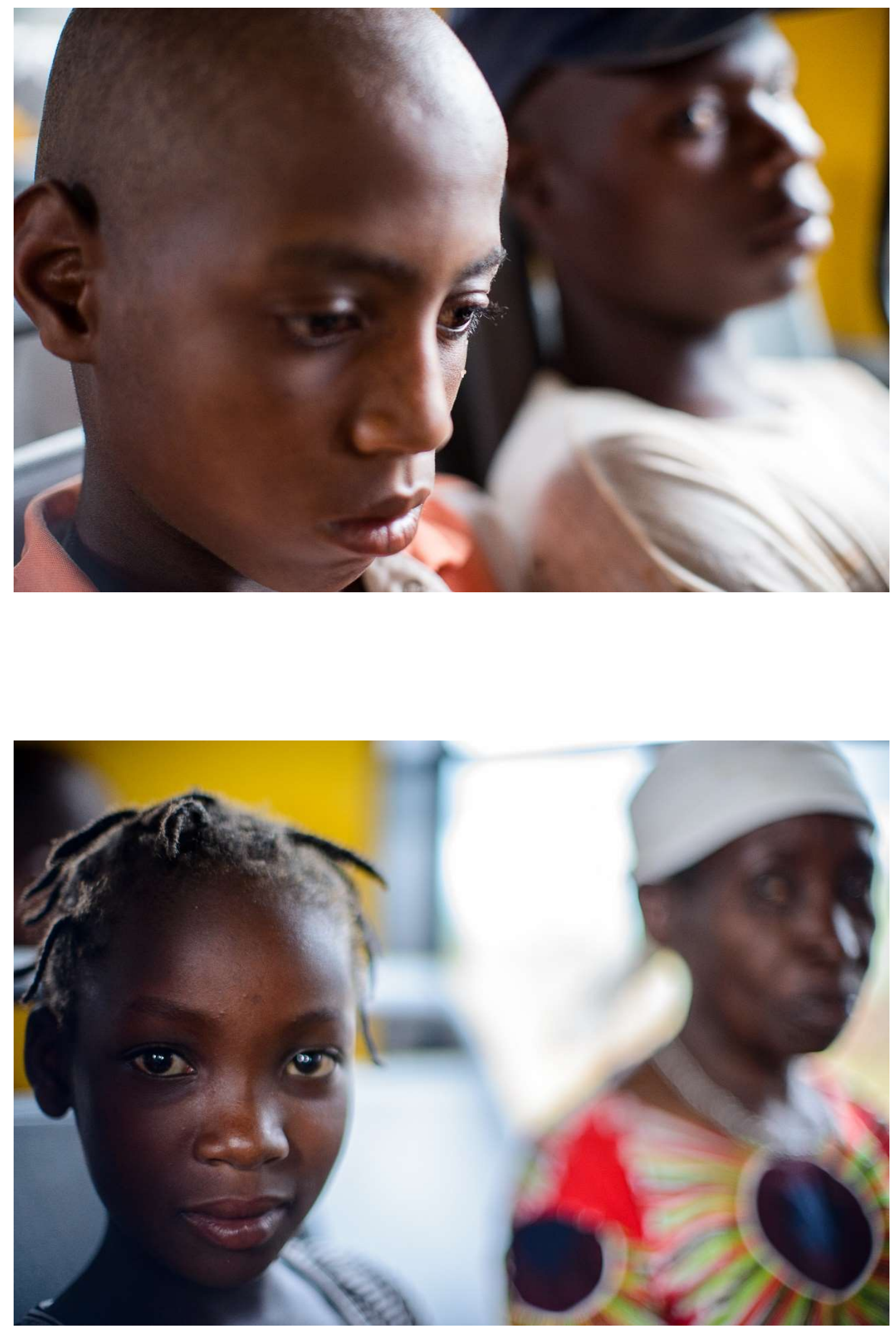

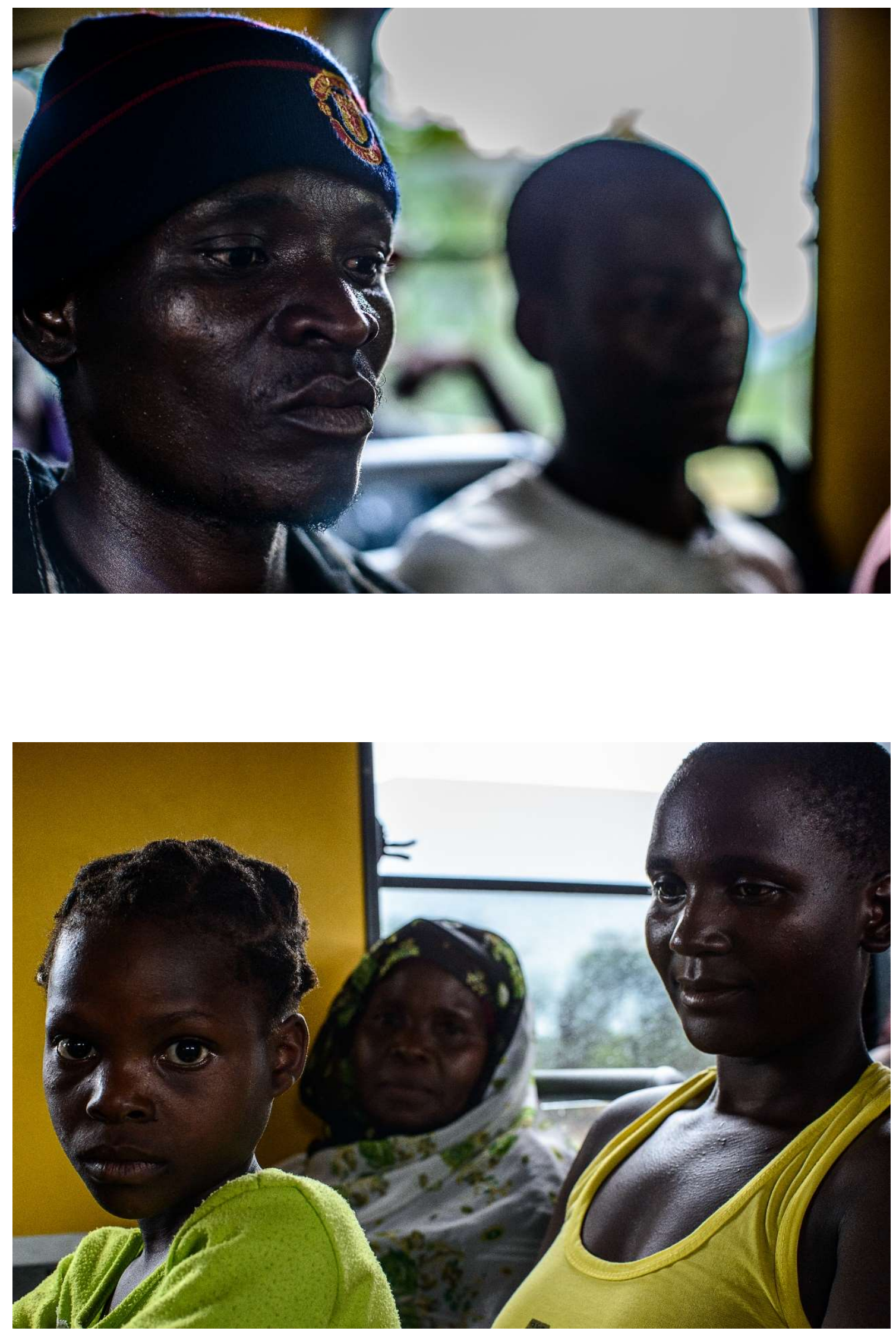

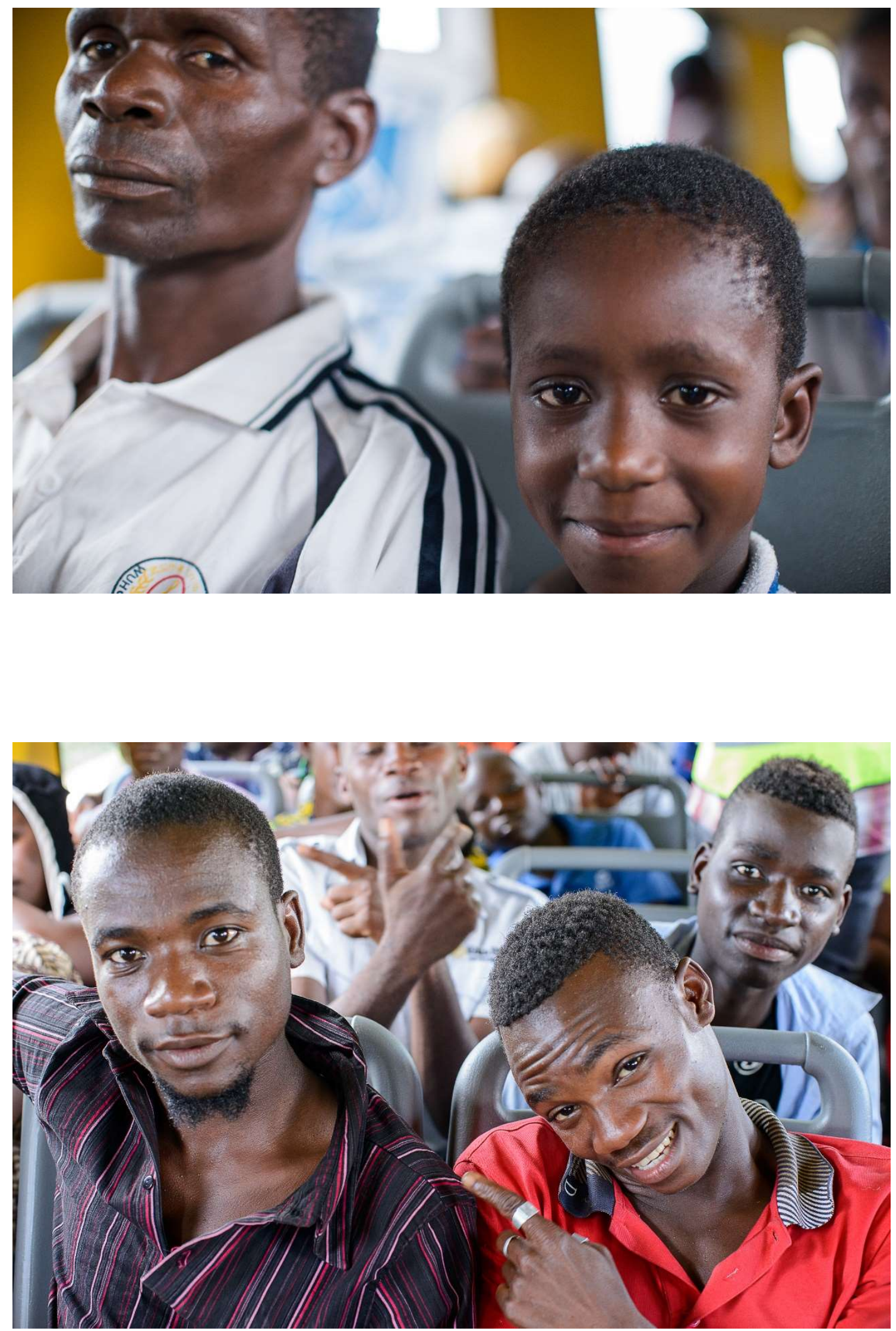

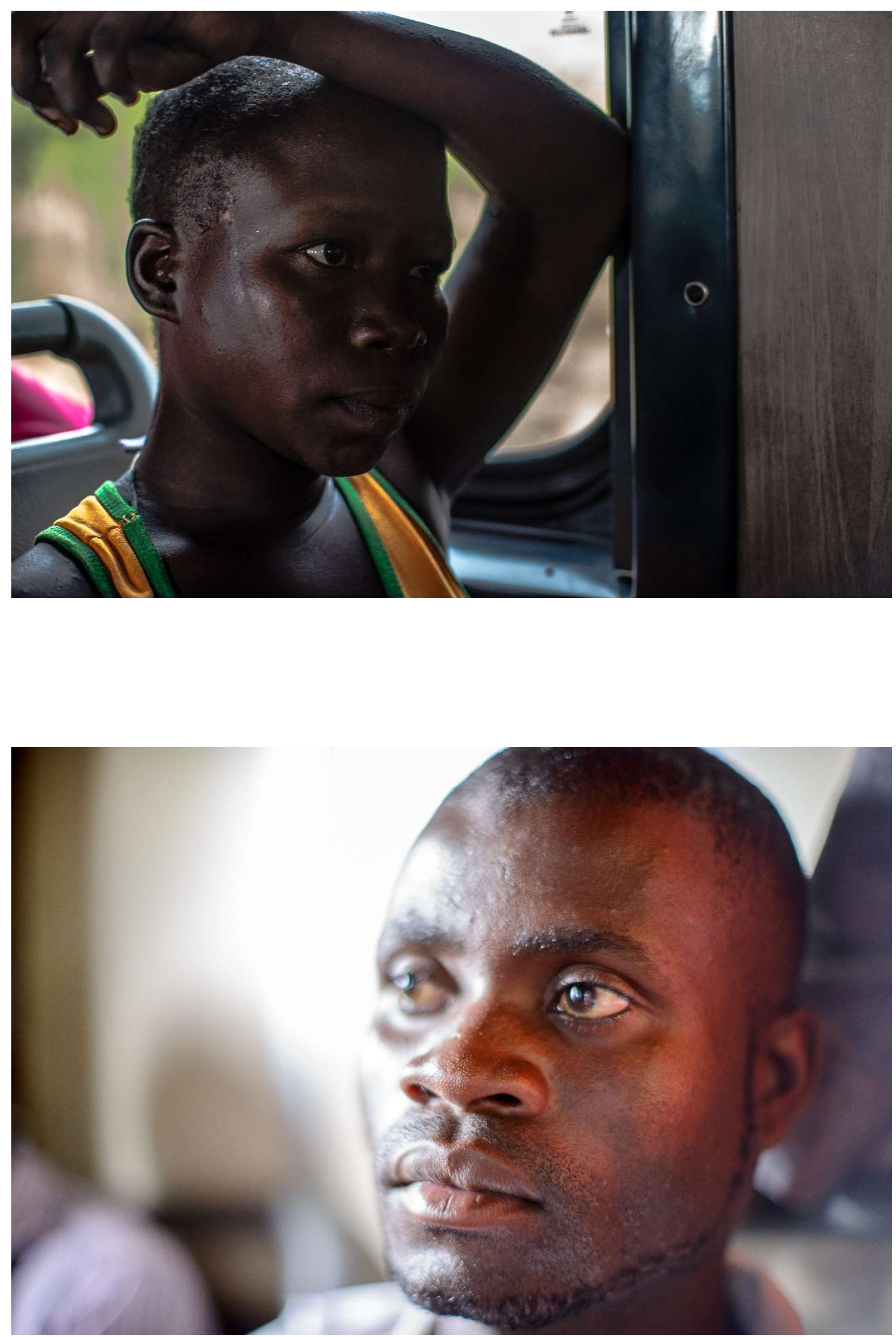


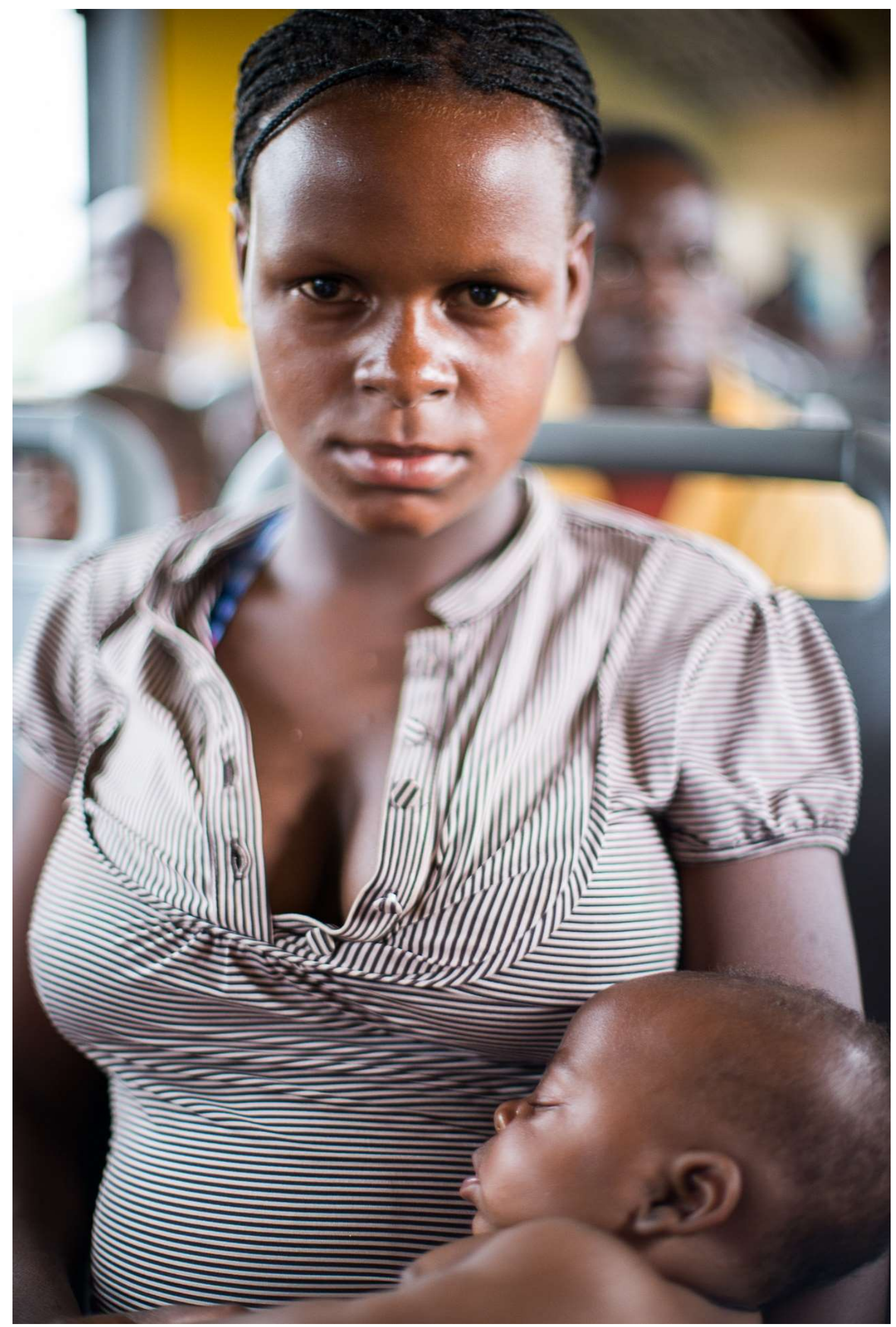




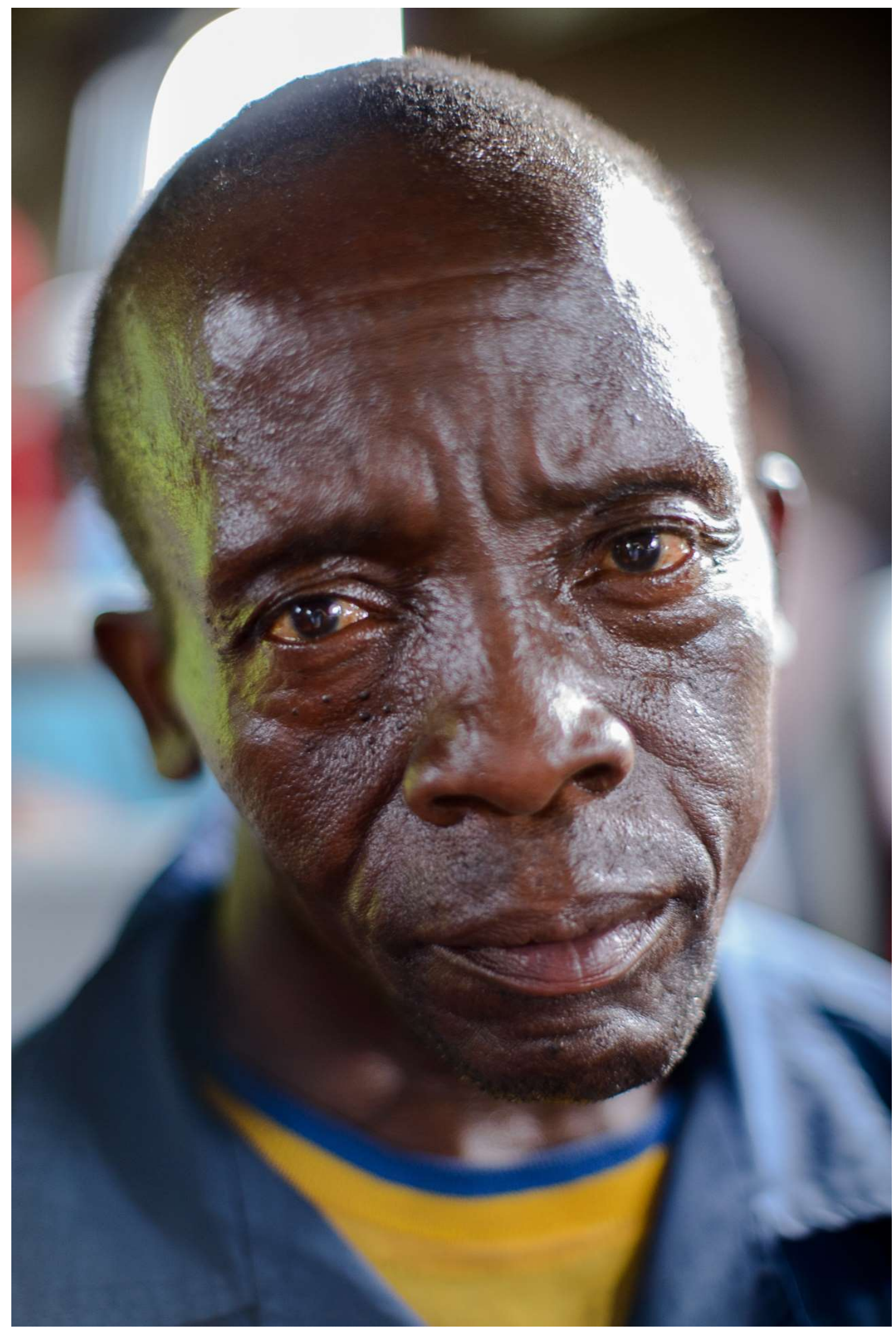




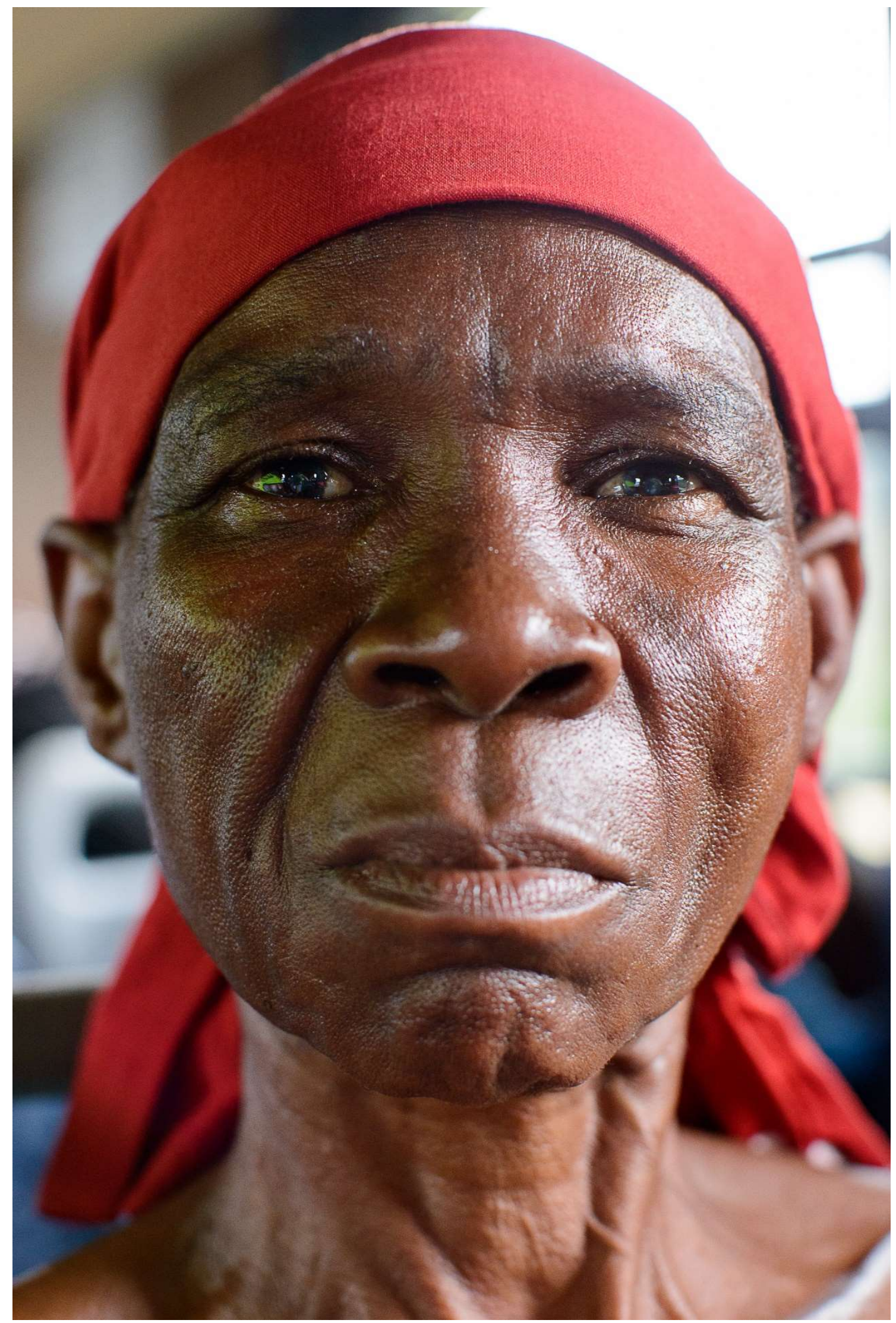




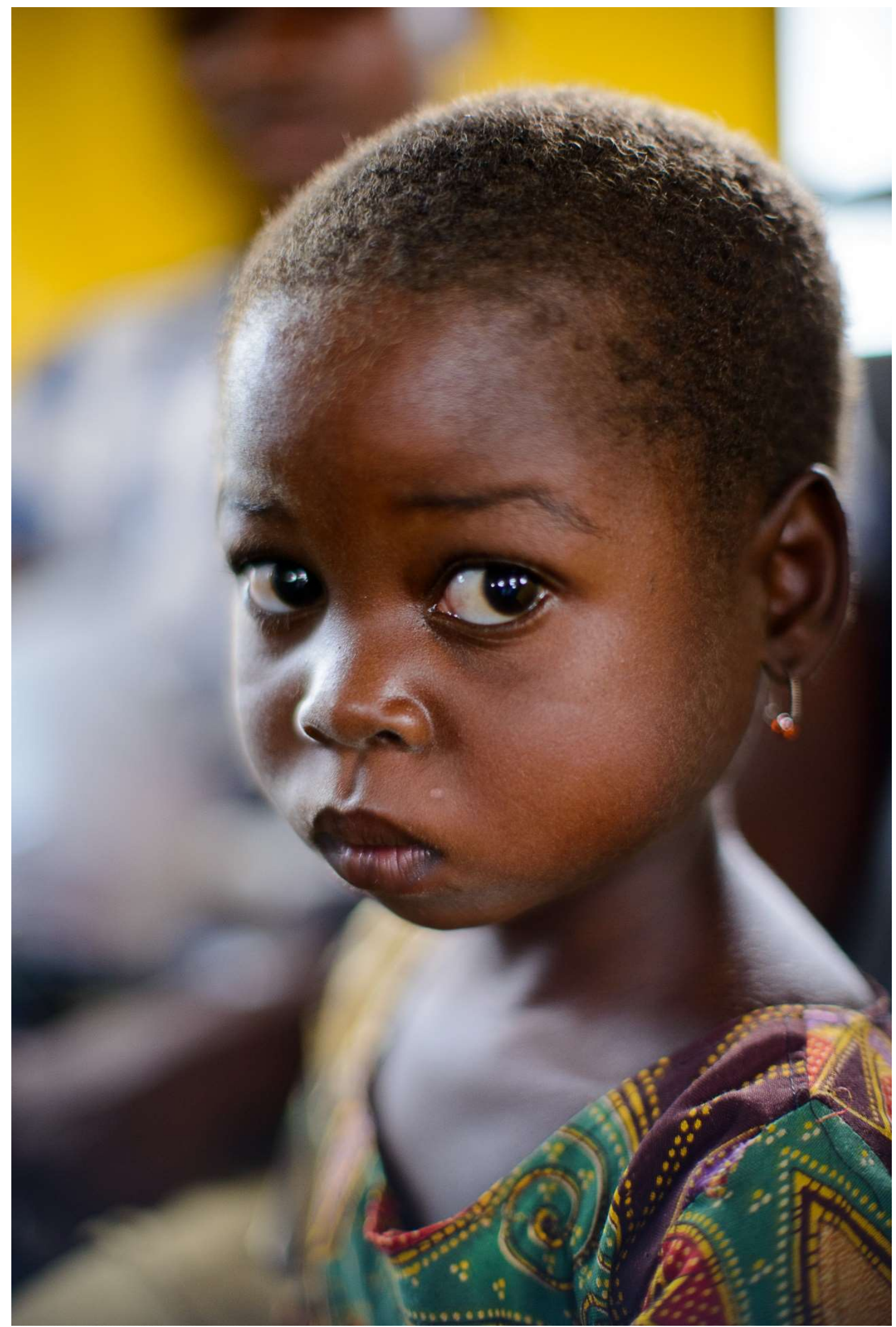

